\title{
Accidents black spots on highways and their low cost remedial measures
}

\author{
I. Hafeez \& M. A. Kamal \\ Department of Civil Engineering, \\ University of Engineering and Technology, Taxila, Pakistan
}

\begin{abstract}
It is imperative to identify and analyze the presence of black spots on highways with key causes of road accidents that have taken place previously. It is quite difficult to investigate and analyze the available accident data, mainly because of geometric conditions, traffic and vehicles speeds. It has been revealed in this study that most of the accidents at black spots occurred due to speedy and aggressive driving of road users. Geometric conditions have comparatively less contribution in accidents. Furthermore, most of the accidents happened in broad day light rather than at night. In order to have safe and smooth flow of traffic on urban highways, encroachments within the right of way should be cleared off and separate service roads should be provided for local traffic. Low cost remedial measures like road marking, signs, signals, enforcement, slight geometric improvement can reduce the black spots.
\end{abstract}

Keywords: accidents, black spot, highways, remedies.

\section{Objective of study}

The main objective of this study is to highlight importance of accident record keeping, analysis of facts, identify accidents black spots and to provide suitable low cost remedial measures. How existing available accident data can be analyzed and processed in order to address the main causes of the crashes with respect to vehicle, road characteristics at specific locations and road user's psychology in Pakistan. How each and every black spot can be treated independently based on its nature, size and intensity of accidents. This can be done in a systematic way so that a better, safer and convenient road traffic system can be developed. Most of the accidents are not merely due to some 
serious causes, but ignorance of some minor causes may resulted major accidents. It also emphasized the need to understand the importance of minor weakness and flaws in the road traffic system and their low cost remedial measures.

\section{Introduction}

Pakistan came into being in 1947 with a meagre resources and deplorable highway infrastructures. The population of the country has increased by over five fold since independence, from around 30 millions to 155 million. The increase in population, density, strong urbanization and diversification in land use has resulted in increased demand for mobility and now requires efficient transport systems for economic prosperity and social integration. With the increase in the highway networks and efficient mobility services, rate of accidents also increased. Most of the existing network is in dangerously poor condition. In 2002, the total account of vehicles in the country is about 49 million, out of which nearly $50 \%$ are motorcycles and $15 \%$ agriculture tractors. The growth of vehicle population has been $8.5 \%$ during the last ten years. The road transport is almost entirely in private sector. The traffic in Pakistan is one of the most chaotic and in-disciplined in the world. Hardly anybody seems to pay any attention to traffic rules and everybody behaves as he pleases. As a result accident rates are high and numbers of road fatalities are increasing every year in Pakistan [1]. One of the serious factors behind Pakistan's high fatality rate is the road accidents which have been increasing day by day alarmingly as compared with other country of the world. Pakistan is the 4th highest among 29 countries in this scenario [2]. Insufficient availability of accident information and control systems perhaps aggravate the condition. It is the need of the era to develop such systems, where improvement in the road safety conditions by analyzing the available accident data can be possible.

Globally, road fatalities are expected to continue to increase with a fatality toll between 900 thousand and 1.1 million in 2010 and reach between 1.1 million and 1.3 million in 2020 [3]. Trend data shows that the total number of people killed in road crashes in regions of the developing world continues to increase, whereas in the West there has been a steady decrease over the last fifteen years or so [4].

\section{Literature review}

\subsection{Accident}

Accident is defined as an error in driver-vehicle-roadway system and it must be recognized that different types of accidents are caused due to different at any given location namely, rear-end, side-swipes, head-on, night-time, bad-weather, etc. for instance, predominance of rear-end accidents will indicate slippery pavement whereby the drivers have difficulty in stopping in time. Side-swipe accidents will indicate ambiguous traffic control devices, causing confusion 
among the drivers regarding right-of-way. Head-on collisions signify lack of adequate sight distances at the location. Predominance of night-time accidents at the location will indicate serious problems with night time visibility. Badweather accidents can results due to a road pavement which becomes dangerously slippery when wet or it may be due to inadequate signs for inclement weather. Similarly, there are numerous other types of accidents which occur due to a variety of reasons. The job of the accidents analyst is, therefore, to relate the accidents experience at any location to one or more causes. The state of the art permits such treatments [5].

\subsection{Black spots (BS)}

According to previous studies, black spot was originally defined as "a road location of limited are with a high concentration of accidents". The term "Black spots" is said to derive from the method that was originally used to identify hazardous sites. Accidents were pinpointed on a map, using coloured pins to represent the trauma severity of each of these events. Black was reserved for accidents having caused property damage only and the significant proportion of these accidents created black dots at concentration points. There is no universally accepted definition of a Black spot to the best knowledge of the author. The terms "hazardous location" and "high accident locations" often used as synonym. This definition has progressively evolved as several researchers now recommend including the concept of "Potential for Improvement (PI)".

\section{Accidents facts analysis}

According to data compiled by the Federal Bureau of Statistics in year 2001 through 2007, as reported in Table 01, the number of road accidents has been increasing [6].

Table 1 has shown that number of persons killed to vehicle involved ratio in each year is above $47 \%$, while injury to vehicle involved ratio is about $100 \%$ every year. An average rate of fatal accident per annum as compared with the total accidents recorded during the last six years is $43 \%$. In each year, ratio of people killed to number of accidents is more than $50 \%$, while injury to accident rate is more than $100 \%$. From the above facts, it may be concluded that, "if an accident occur and the vehicle had three people inside, one out of three will obviously be killed, while two will get injuries". On the whole, increasing rate of accidents has been observed since 2002 .

According to the last study conducted by National Transport Research centre, Pakistan on causes of 1585 accidents occurred in 1987-93, as given in Table 2, geometry of the road caused fever accidents. Other road related factor like surface conditions, shoulder and median conditions, road under construction, and lack of road safety device involved greatly towards serious accidents.

It may be seen from Table 2 , that out of $1585,1344(85 \%)$ vehicles were on straight, flat and median road. Whereas only 119 (8\%) vehicles were on curved roads at the time of accidents. But that was not primary cause of an accident. Road surface type and surface condition have also been examined. The shoulder 
width and shoulder type of the roads, where a total of 1585 accidents have been reported, has given in Table 3 .

Table 1: Data on traffic accidents in Pakistan.

\begin{tabular}{|c|c|c|c|c|c|c|}
\hline \multirow[t]{2}{*}{ Year } & \multirow{2}{*}{$\begin{array}{c}\text { Total } \\
\text { Number of } \\
\text { Accidents }\end{array}$} & \multicolumn{2}{|c|}{ Accident } & \multicolumn{2}{|c|}{ Person } & \multirow{2}{*}{$\begin{array}{l}\text { Total number of } \\
\text { Vehicles involved }\end{array}$} \\
\hline & & Fata & Non-Fatal & Killed & Injured & \\
\hline 2001-02 & 10033 & 4379 & 5654 & 5248 & 11922 & 10765 \\
\hline 2002-03 & 9377 & 4045 & 5332 & 4813 & 10643 & 10100 \\
\hline 2003-04 & 10308 & 4184 & 6124 & 5199 & 12927 & 10852 \\
\hline 2004-05 & 9896 & 4250 & 5646 & 5112 & 12401 & 10912 \\
\hline 2005-06 & 9492 & 4115 & 5377 & 4868 & 11415 & 10565 \\
\hline $2006-07$ & 10466 & 4535 & 5931 & 5465 & 12875 & 11481 \\
\hline \begin{tabular}{|l} 
January \\
2007-Jan. \\
2008
\end{tabular} & 11350 & 5007 & 6343 & 5996 & 13392 & 12418 \\
\hline
\end{tabular}

Table 2: $\quad$ Accidents due to road geometry.

\begin{tabular}{|l|l|l|l|l|l|}
\hline Median & Straight Flat & Curvature & Gradient & Both & Total \\
\hline Yes & 426 & 29 & 4 & 30 & 489 \\
\hline No & 918 & 90 & 37 & 51 & 1096 \\
\hline & 1344 & 119 & 41 & 81 & 1585 \\
\hline
\end{tabular}

Table 3: Accidents due to shoulder characteristics.

\begin{tabular}{|c|c|c|c|c|c|}
\hline \multirow{2}{*}{$\begin{array}{l}\text { Shoulder } \\
\text { Type }\end{array}$} & \multicolumn{4}{|c|}{ Shoulder Width (m) } & \multirow[t]{2}{*}{ Total } \\
\hline & 0 & 1 & 2 & 3 & \\
\hline Paved & - & 214 & 164 & 65 & 443 \\
\hline Un-Paved & - & 306 & 342 & 217 & 865 \\
\hline No Shoulder & 277 & - & - & - & 277 \\
\hline Total & 277 & 520 & 506 & 282 & 1585 \\
\hline
\end{tabular}

It may be seen from the above that ratio of accidents on road with $1 \mathrm{~m}$ and $2 \mathrm{~m}$ wide shoulder is almost twice that compared to no-shoulder and $3 \mathrm{~m}$ wide shoulder. Similar analysis was made on junction type and results are given in Table 4. 
Table 4: $\quad$ Accidents due to junction type.

\begin{tabular}{|l|l|l|l|}
\hline Junction Type & Total & Junction Type & Total \\
\hline Non-Junction & 1048 & y-Junction & 7 \\
\hline Cross & 130 & Round & 52 \\
\hline T-Junction & 154 & Other & 170 \\
\hline Stag-X & 24 & Total & 1585 \\
\hline
\end{tabular}

It may be seen in Table 4 that out of $1585,1048(66 \%)$ occurred at nonjunction and minimum number at Y-Junction. Out of the total accidents $38(2 \%)$ were observed due to road under construction.

Three black spots, motorway, national highway and an urban road were studied based on the observations of Police Stations, Locals, Highway Authorities, Traffic Police, Motorway Police and Hospitals etc. The objectives and outcomes of this study are to assess the problems and then to increase road safety in the selected road segments by reducing the overall number and severity of road accidents by the application of low cost-effective measures on existing roads as a basis of accident reduction. Installation of road furniture and other safety measures result very fewer report on any accidents on the same locations.

\section{Causes of black spots and their remedial measures}

Insufficient law enforcing agencies, improper road infrastructure, lack of proper warning signs, inadequate illumination on footpaths and cycle tracks, poor emergency response capability and injustice in the implementation of traffic laws are the main causes of road accidents. Transporters do not care for the fitness of their vehicles and keep on modifying the chassis/ frame of their vehicles without engineering specifications. They equip their vehicles with illegal and inappropriate manner and engage such drivers who are alcoholics and drug users on low wages. Lack of proper driving school also leads to accidents;

While conducting black spot study in an urban area, after collecting the accident's information from respective agencies, police stations, analysis of the location should be made using spot speed studies, vehicles classification and driver studies, cost benefits and other relevant set of studies. Further steps adopted for analysis of black spots are: recording the accidents and data entering onto computer; finding sites with high number of accidents and commonly known as black spots; weight sites for severity and exposure. Initial accident investigation and site visits; rank sites for in depth investigation; collection of further data from accident forms/site studies; analysis of data; more detective work; human factors; select and check packages of counter measures; rank sites for treatment, implementation and construction; monitor behaviour during first days and months; evaluate the effects on accidents and cost-benefit analysis.

\subsection{Visibility effects}

Poor visibilities, inadequate sight distance, braking distances especially on curves are the major factors in the creation of black spots. At grade intersection, 
if links are not properly designed they may create visibility problem in the driver's vision. Adequate sight distance as provided by AASHTO, Green book [7] helps drivers to safely negotiate the hazards while travelling at design speed.

If there is insufficient street lighting at night, or the sun is low on the horizon, in mist, during rain, fires or storms, reduce the speed below the speed limit. These conditions reduce vision and prevent a driver from reacting in time to hazardous situations. If accident occurs on highways, it should be investigated on the basis of degree of damage or severity of damage. According to AASHTO, if tyre braking impressions are present on road, we can assume suitable data and work out the speed at which the vehicle hit the object by using equation 1 . Where in driver eye height and object height is assumed as 3.5 feet and 2 feet respectively.

$$
\text { Braking distance }=\frac{V i^{2}-V f^{2}}{30(e+G)}
$$

With the help of this equation, it can clearly be estimated that vehicle was traveling with the speed limits at the time of accidents or not. It gives us the real cause of accident in term of over speeding, surface friction or unsafe sight distance.

\subsection{Geometric effects}

Wrong and incompatible geometric designs may leads to sever accidents. Number of black spot in the road length depends on many factors. In plan areas and straight alignment of the road, design speed, visibility, width and number of lanes, shoulders width and conditions and median types have great effects towards the safe movement of vehicles and its service capacity. It further depends upon the type of roads on its functional classification. In rolling and mountainous terrains, maximum and minimum grade, critical length of upgrade, provision of climbing lanes, presence of hidden dips, roller coasters, sky line horizons, selection of curve type, width and number of lanes are the major geometric parameters that has mainly be concerned with the black spot identifications.

Criteria defined by AASHTO for maximum grade are based mainly on studies of the operating characteristics of typical heavy trucks. Table 5 shows the maximum grades permitted for urban arterials [7].

Table 5: $\quad$ Maximum grades for urban Arterials.

\begin{tabular}{|l|l|l|l|l|l|l|l|l|l|}
\hline \multirow{3}{*}{ Type of Terrain } & \multicolumn{9}{|l|}{ Design speed (mph) } \\
\cline { 2 - 12 } & 40 & 45 & 50 & 55 & 60 & 65 & 70 & 75 & 80 \\
\cline { 2 - 11 } & \multicolumn{7}{|l|}{ Maximum Grade (\%) } \\
\hline Level & 5 & 5 & 4 & 4 & 3 & 3 & 3 & 3 & 3 \\
\hline Rolling & 6 & 6 & 5 & 5 & 4 & 4 & 4 & 4 & 4 \\
\hline Mountainous & 8 & 7 & 7 & 6 & 6 & 5 & 5 & 5 & 5 \\
\hline
\end{tabular}


For short length and one way down grades highways with less than $500 \mathrm{ft}$ tangent, maximum grades may be $1 \%$ steeper than given in Table 6 . One of the important aspects behind black spots at curves is the attainment of superelevation through tangent run out and run off distances. According to AASHTO, $66 \%$ super-elevation should be attained on tangent and $33 \%$ on curve length. It should be attained $100 \%$ on runoff if transition curve is provided. Moreover rate of transition of edge line from normal crown or cross slope to full superelevation traditionally taken at $0.5 \%$. Current recommendation varies from $0.35 \%$ at $80 \mathrm{mph}$ to $0.8 \%$ for $15 \mathrm{mph}$ (with full adjustments for number of lanes). If super-elevation does not attained according to the standard criteria as described by the agencies, curve area becomes hazardous especially for high speed vehicles Maximum effort should be to avoid sharp horizontal curvature to be introduced near bottom of steep grade near the low point of a pronounced sag vertical curve[7].

\subsection{Over speeding and reckless driving}

Speed is an important transportation consideration because it relates to safety, time, comfort, convenience, and economics. On account of the measures, which have been taken, the citizen has readily accepted the system of policing introduced on the motorway. In a little over three years the Motorway Police has penalized 146,752 offenders mainly due to over speeding. Only 470 contested police action and there have been no complaints with regards to their conduct [8]. The solution to over speeding and aggressive driving is to check the vehicle's spot speed on the roadway.

\subsection{Human errors}

The key factor behind the human behaviour towards road accidents is the age, profession, education and standard of living or the financial status. It has been observed that youngsters tend to be fast drivers than aged persons. Although this trend exists for both men and women, but women do not drive as fast as their male contemporaries and this habit pertains to an age of about 40 years [9]. According to National Research Centre Data Bank, human error was the sole cause in $57 \%$ of all accidents and was a contributing factor in over $90 \%$. In contrast, only $2.4 \%$ were due to mechanical fault and $4.7 \%$ by environmental factors. The reasons why humans make so many driving mistakes are to be looked into the inherent limitations of human information processing. Humans must rely on three fallible mental functions: perception, attention and memory. The identification of the problems based on the above stated facts which are related to drivers and vehicles can provide guidelines for future efforts in the direction of crash and black spots avoidance [10].

\subsection{Vehicular conditions}

Contribution of static and dynamic characteristics of vehicles can not be denied in the analysis of black spots. Static characteristics of vehicle affecting road 
design are the dimensions, weight and height of driver's seat, clearance and maximum turning angle of vehicle. Where as dynamic characteristics of vehicles affecting road design are speed, acceleration, vehicle stability, braking characteristics and some aspects of vehicle body design.

\subsection{Education factor}

Recently as a pilot project, Govt. has employed a fleet of educated officers on highways to control the accident ratio, in the absence of which, drivers endanger not only their lives but also the lives of others. In order to effectively implement the road safety programme, it is imperative to ensure that the key players possess the skills to accomplish what is required to them. The drivers should be allowed on the roads only after assuring that they have achieved an acceptable level of proficiency. The establishment and running of reputable Driver Training Schools in all large cities is a fundamental requirement.

\subsection{Time of day}

Early hours of the morning and the middle of the afternoon are the peak times for fatigue accidents and long journeys on monotonous roads, particularly on motorways, and mostly drivers fall in sleeps during that period of the day. There are difficulties in determining the level of sleep related accidents because there is no simple and reliable way for an investigating police officer to determine whether fatigue was a factor in an accident. This result in varying estimates of the level of sleep related accidents. A study of road accidents between 1987 and 1992 found that sleep related accidents comprised $16 \%$ of all road accidents and $23 \%$ of accidents on motorways [10].

\subsection{Excessive encroachments}

Vehicular access for residential and commercial areas involves provision of frontage access for the free flow of through traffic. The situation becomes more crucial when it is provided at primary roads. People take advantage of direct access and establishment encroachments along the access and even primary roads can often be seen. Most of the accidents occur due to land occupied along the road and excessive pedestrian's movements, parking, sellers, passenger's movements etc.

\subsection{Accident reporting centres}

The planning and implementation of a comprehensive policy is a necessity in developing a countrywide strategy related to traffic management. Planning for the future is necessary, and in this context it is strongly recommended to compile all relevant information about accidents would be readily available for analysis and thereby assist in decision making. It is therefore proposed, that Accident Reporting Centres (ARCs) should be established at major cities to undertake this task. 


\subsection{Provision of traffic calming devices}

According to Montgomery County, Maryland department, Traffic calming can be defined as a set of street designs and traffic rules that slow and reduce traffic while encouraging walkers and bicyclists to share the street. Traffic calming has the objectives, including slowing traffic speed, reducing cut-through traffic and increasing safety of pedestrians, bicyclists and vehicles on streets, urban collectors and urban arterials. Selection and implementation of specific traffic calming tool depends upon its appropriate application. In urban highways and street of Pakistan, vertical deflection type traffic calming devices like speed humps, speed cushion, and horizontal deflection type devices like roundabouts, prove to be more efficient and economical. Speed humps are rounded raised areas placed across the road. Based on driver's psychology, current practice of speed hump is different in Pakistan as compared to Institute of Transportation Engineers (ITE), UK design. The speed humps are normally 6 feet long and 6 inches high than ITE design of 12 feet long and 3 to 4 inches high.

\section{Conclusion and recommendations}

- Major causes behind the high accident rate in Pakistan are the lack of proper system to record and control accident black spots. In each accident, rate of death is $30 \%$. Accidents never happened due to single cause, but it involves many factors that have to investigate thoroughly before concluding the results.

- Systematic accident reporting and recording centres must be established with the help of different highways agencies, so that regular monitoring and identification of black spot can be possible. Deficiency in Geometric design play a significant rule towards accident, which should be checked and counter measured with engineering concepts.

- Most of the accidents are not merely due to some serious causes, but ignorance of some minor causes may results major accidents. It also emphasizes the need to understand the importance of minor weakness and flaws in the road traffic system and their low cost remedial measures.

- Lack of proper warning signs, road markings, signals, inadequate illumination on footpaths and cycle tracks, poor emergency response capability and injustice in the implementation of traffic laws are the main causes of road accidents.

\section{References}

[1] World Bank country report about Pakistan, May 2005.

[2] Japan International Cooperation Agency, "A Fact Book on Pakistan Transport" 2006.

[3] Asian Development Bank (1998), vulnerable road users.

[4] World Health Organisation (1997). World health statistics 1996 
[5] National Transport Research Centre, Pakistan. “Accidents Study by NTRC”, Report No. NTRC-130.1990

[6] Govt. of Pakistan. Statistics Division Federal Bureau of Statistics, 2006.

[7] AASHTO, A Policy on design of urban highways and arterial streets, 1973.

[8] National Transport Research Centre, Pakistan. "Accidents Study by NTRC”, Report No. NTRC-130. 1990.

[9] National Transport Research Centre, Pakistan. "Psychological attitudes towards Highway Safety”, Report No. NTRC-37. 1981.

[10] National Transport Research Centre, Data Bank, Pakistan. 